\title{
AVALIAÇÃO DA CAPACIDADE IMUNOESTIMULANTE E DA ESTABILIDADE DE UM PROBIÓTICO EMPREGADO EM RAÇÕES DE CÃES
}

\author{
(Evaluation of immunostimulant capacity and stability of thermo stable probiotic \\ used in the diet of dogs)
}

\author{
GONÇALVES, M. ${ }^{1}$; MALUTA, R.P. ${ }^{2}$; DAHLKE, F. ${ }^{3}$; MAIORKA, A. ${ }^{3 *}$; ÁVILA, F.A. ${ }^{4}$ \\ ${ }^{1}$ Médico Veterinário da Matsuda Minas Ltda, São Sebastião do Paraíso - MG. \\ ${ }^{2}$ Aluno de Pós Graduação em Microbiologia, FCAVJ-UNESP, Jaboticabal-SP. \\ ${ }^{3}$ Departamento de Zootecnia da UFPR, Curitiba-PR, Pesquisador do CNPq. \\ ${ }^{4}$ Microbiologia, FCAVJ-UNESP, Jaboticabal-SP, Pesquisador do CNPq.
}

\begin{abstract}
RESUMO - Foi avaliado um probiótico termo-resistente, liofilizado e encapsulado, composto de Bacillus cereus (ATCC 9634) 4,0 × $10^{8} \mathrm{UFC} / \mathrm{g}$ e Bacillus subtilis (CCT 3131) 4,0 x $10^{8} \mathrm{UFC} / \mathrm{g}$, incorporado em uma ração comercial para cães com o objetivo de avaliar sua viabilidade durante o período de um ano, e o seu efeito imunoestimulante quando fornecido às dietas. No primeiro experimento, foi avaliada a sobrevivência das bactérias quantitativamente e qualitativamente depois de $3,6,9,12$ meses de estocagem. No segundo ensaio, foram utilizados 10 cães (machos e fêmeas) com peso variando de 10 a $30 \mathrm{~kg}$, sem raças definidas, divididos em dois grupos de cinco animais cada. Todos os animais sem título sorológico anti-leptospira, foram vacinados contra os sorovares canicola e icterohaemorrhagiae no início do experimento e mantidos em canis individuais durante 60 dias. Os animais do grupo I receberam ração extrusada acrescida de Probiótico TR e, os animais do grupo II receberam a mesma ração extrusada sem o Probiótico TR, sendo mantidos como controles. Os títulos de anticorpos contra os sorovares canicola e icterohaemorrhagiae foram determinados antes da vacinação, no $15^{\circ}, 30^{\circ}$ e $60^{\circ}$ dia após, utilizando a reação de soro-aglutinação microscópica com antígenos vivos. Pelos resultados da contagem total de esporos nas rações extrusada e farelada, o probiótico TR é notadamente estável por período superior a 12 meses. 0 estímulo da resposta imune foi verificado pela elevação dos títulos dos animais do grupo I no $15^{\circ}, 30^{\circ}$ e $60^{\circ}$ dia após a vacinação. Este fato é atribuído à ingestão do probiótico TR, uma vez que entre os animais que não receberam ração com probiótico TR (grupo II), a resposta imune foi menor e instável.
\end{abstract}

Palavras-Chave: Bacillus cereus; Bacillus subtilis; cães; extrusão; Probiótico.

\begin{abstract}
The time of viability of a thermostable probiótica (TR) in extruded and mealy formulations for dog food and their imunoestimulant effects in dogs were evaluated. A commercial, lyophilized, thermostable and encapsulated probiotic, composed of Bacillus cereus (ATCC 9634) 4,0 $\mathrm{x}$ $10^{8} \mathrm{UFC} / \mathrm{g}$; Bacillus subtilis (ATCC 3131) 4,0 $\times 10^{8}$ UFC/g, was incorporated in an extruded and in a mealy commercial dog food. In one experiment, quantitative and qualitative survival ratios of bacteria were evaluated at 3, 6, 9 and 12 months of storage. In other, 10 dogs (males and females) with weight varying from 10 to $30 \mathrm{~kg}$, without defined breeds, were divided in two groups of five animals each. All animals without serological titre anti-leptospiras were vaccinated against the serovares canicola and icterohaemorrhagiae in the beginning of the experiment and maintained in individual facilities for 60 days. The animals of group I received extruded ration with Probiotic TR and the animals of group II received the same extruded ration without Probiotic TR (controls). The antibodies' titres against serovares canicola and icterohaemorrhagiae were determined before vaccination, and at $15^{\circ}$, $30^{\circ}$ and $60^{\circ}$ day after, using microscopic serumagglutination reaction with live antigens. According to the results of total count of spores in extruded and mealy rations, the probiotic TR was stable for a superior period than 12 months. The stimulation of the immune response was verified by elevation of serological titres from group I animals at $15^{\circ}$., $30^{\circ}$. and $60^{\circ}$. day after vaccination while the control dogs showed lower and unstable responses.
\end{abstract}

Key Words: Bacillus subtilis; Bacillus cereus; extrude dog food; Probiotic.

\footnotetext{
* Autor para correspondência: departamento de Zootecnia, SCA, UFPR. Rua dos Funcionários, 1540, Curitiba, PR. CEP 80035050.
} 
Avaliação da capacidade imunoestimulante e da estabilidade de um probiótico empregado em rações de cães

\section{INTRODUÇÃO}

Os Probióticos são bactérias ou leveduras, vivas, que podem ser acrescentadas à alimentação com o propósito de regular a microbiota intestinal do hospedeiro (SCHREZENMEIR e DE VRESE, 2001).

Os Probióticos têm sido usados terapeuticamente no tratamento de diarréia ou profilaticamente, em humanos e animais, para minimizar os efeitos da diminuição da microbiota intestinal devido à antibioticoterapia ou a gastrenterite (BARROWS e DEAM, 1985; LESTRADET, 2005).

É sabido que os Probióticos têm efeitos benéficos na saúde dos hospedeiros (FULLER, 1989), entretanto, seus mecanismos de ação não estão completamente elucidados. Supostamente, atuam como bio-reguladores da microbiota intestinal agido como uma fonte de enzimas digestivas e/ou fatores estimulantes no sistema imune (LESTRADET, 2004). A fim de melhorar o desenvolvimento ponderal, o desempenho reprodutivo e diminuir estresses (alta concentração de animais, desmama precoce ou crescimento rápido) têm sido utilizados rotineiramente probióticos na alimentação de bovinos (ÁVILA et al., 2000) associado com sistema moderno de criação (LESTRADET, 2004).

LIKIMANI e SOFOS (1990) estudaram a resistência de esporos de Bacillus globigii durante extrusão de uma mistura de milho/soja. Os autores concluíram que nas temperaturas de extrusão mais altas $\left(100^{\circ}, 120^{\circ}\right.$ e $\left.140^{\circ} \mathrm{C}\right)$ os efeitos destrutivos à viabilidade são grandes, apesar de haver também diminuição do número de esporos à temperatura de $80^{\circ} \mathrm{C}$. BIOURGE et al. (1998) relataram que a resistência do Bacillus CIP 5832 ao processo de extrusão é mínima e resulta em perda de $99 \%$ de esporos. Desta forma, para não haver perda considerável da eficiência de um probiótico contendo estes microorganismos, o mesmo deve ser adicionado à ração após o processo de extrusão.

Desmama, mudanças dietéticas e de local são as condições mais freqüentes que afetam a microbiota intestinal de cães e são as situações nas quais os Probióticos podem ser recomendados. Os Probióticos também podem ser benéficos para cães que vivem em grandes colônias ou vendidos em "pet shops" nos quais é grande a concentração animal, pressão de infecção e tensão que podem afetar negativamente na resistência imune do animal. Baseado nestes fatos foi realizado o presente estudo com os objetivos de avaliar o tempo de viabilidade de um probiótico Termo Resistente em ração farelada e extrusada e o seu efeito imunoestimulante em cães vacinados contra os sorovares canicola e icterohaemorrhagiae.

\section{MATERIAL E MÉTODOS}

\section{EXPERIMENTO 1:}

Foi avaliada a viabilidade de um probiótico liofilizado, termo-resistente, encapsulado (KRASAEKOOPT et al. 2003), composto por Bacillus cereus (ATCC 9634) 4,0 × $10^{8} \mathrm{UFC} / \mathrm{g}$ e Bacillus subtilis (ATCC 3131) $4,0 \times 10^{8} \mathrm{UFC} / \mathrm{g}$, adicionado a uma ração extrusada ou farelada para cães, em nível de inclusão de $2 \mathrm{~kg}$ por tonelada de ração.

Ambas as rações possuíam a mesma composição química ( $28 \%$ de Proteína Bruta, $9 \%$ de Extrato Etéreo, $5 \%$ de Matéria Fibrosa, 4\% de Matéria Mineral, $2 \%$ de Cálcio e $1 \%$ de Fósforo), entretanto, na ração extrusada o probiótico foi adicionado à ração após o processo de extrusão (temperatura de $70^{\circ}$ a $80^{\circ} \mathrm{C}$ ). Amostras dos dois grupos de ração (farelada e peletizada) foram monitoradas por um período de 12 meses com o intuito de avaliar a viabilidade dos bacilos durante 1 ano. Para este estudo, as amostras das rações foram mantidas em 10 sacos plásticos contendo $8,0 \mathrm{~kg}$, mantidas à temperatura ambiente (Quadro 1), em um local seco, bem ventilado e sobre estrado. A determinação das UFC/g (unidade formadora de colônia por grama de ração) foi determinada em três amostras de $10 \mathrm{~g}$ retiradas de locais diferentes de cada saco de ração farelada e extrusada, seguindo as técnicas descritas por MICHARD e LEVESQUE (1989) e SILVA et al. (2001). Foi avaliada a sobrevivência das bactérias quantitativamente e qualitativamente (contagem média total de Bacillus spp em UFC viáveis por grama) depois de 3, 6, 9, 12 meses de estocagem. 
GONÇALVES, M. et al.

QUADRO 1. TEMPERATURA MÁXIMA (TMAX), TEMPERATURA MÍNIMA (TMIN), TEMPERATURA MÉDIA AMBIENTAL (TMED) E UMIDADE RELATIVA DO AR (UR) NO PERÍODO DE AVALIAÇÃO DA VIABILIDADE DO PROBIÓTICO.

\begin{tabular}{ccccc}
\hline Mês & $\operatorname{Tmax}\left({ }^{\circ} \mathrm{C}\right)$ & $\operatorname{Tmin}\left({ }^{\circ} \mathrm{C}\right)$ & $\operatorname{Tmed}\left({ }^{\circ} \mathrm{C}\right)$ & $\mathrm{UR}(\%)$ \\
\hline Janeiro & 31,3 & 20,3 & 25,0 & 74,7 \\
Fevereiro & 30,7 & 20,3 & 24,2 & 82,9 \\
Março & 31,0 & 20,4 & 24,5 & 81,4 \\
Abril & 29,5 & 17,2 & 22,4 & 74,8 \\
Maio & 26,6 & 12,8 & 18,7 & 70,1 \\
Junho & 27,2 & 12,9 & 18,9 & 66,4 \\
Julho & 28,8 & 13,2 & 20,0 & 60,2 \\
Agosto & 31,0 & 14,7 & 22,0 & 52,5 \\
Setembro & 30,0 & 15,9 & 22,1 & 60,4 \\
Outubro & 30,2 & 18,7 & 23,7 & 72,0 \\
Novembro & 30,6 & 19,0 & 24,1 & 69,3 \\
Dezembro & 29,9 & 20,6 & 24,4 & 82,2 \\
\hline
\end{tabular}

\section{EXPERIMENTO 2:}

Foram utilizados 10 cães machos, com peso variando de 10 a $30 \mathrm{~kg}$, sem raças definidas, divididos em dois grupos de cinco animais cada. Todos os animais, sem título sorológico anti-leptospiras, foram vacinados contra os sorovares canicola e icterohaemorrhagiae no início do experimento e mantidos em canis individuais do Hospital Veterinário da FCAV-UNESP Campus de Jaboticabal/ SP durante 60 dias. Os animais dos dois grupos foram alimentados de acordo com o peso corporal, duas vezes ao dia, recebendo água ad libitum. Os animais do grupo I (Tratamento 1 ) receberam ração extrusada ${ }^{2}$ (Proteína bruta 28\%, Extrato etéreo 9\%, Matéria fibrosa $5 \%$, Matéria mineral $9 \%$, Cálcio $2 \%$ e Fósforo $1 \%$ ) acrescida de Probiótico TR $^{3}$ (termo resistente) na concentração final de Bacillus cereus 1,6 x 10 $\mathrm{UFC} / \mathrm{g}$ e Bacillus subtilis 1,.6 $\mathrm{x}$ $10^{6} \mathrm{UFC} / \mathrm{g}$. Os animais do grupo II (Tratamento 2) receberam a mesma ração extrusada sem o Probiótico TR, mantidos como controle. De cada animal foi determinado o peso corpóreo e foram colhidas amostras de sangue, com e sem anticoagulante (EDTA), antes da vacinação, no $15^{\circ}, 30^{\circ}$ e $60^{\circ}$ dia após a vacinação. Os testes realizados com sangue colhido dos animais antes do início do experimento serviram como controle deles próprios para os hemogramas e título pós-vacinal. Os títulos de anticorpos contra os sorovares canicola e icterohaemorrhagiae foram determinados pela reação de soro-aglutinação microscópica utilizando antígenos vivos (RENDE e ÁVILA, 2003) e das amostras de sangue com anticoagulante foram realizados hemogramas através de contagem automatizada pelo aparelho ABC-VET, usando a técnica ABXS-VET (REBAR et al., 2003). Outros parâmetros subjetivos, como consistência das fezes, foi verificada, durante todo o experimento, conforme o seguinte escore: 1 fezes líquida; 2 fezes pastosas; 3 fezes pouco pastosas; 4 fezes normais e 5 fezes ressecadas.

\section{RESULTADOS}

$\mathrm{Na}$ Tabela 1 é apresentada a estabilidade do Probiótico TR na ração farelada e extrusada durante o período de 3, 6, 9, 12 meses de estocagem.

TABELA 1: CONTAGEM MÉDIA TOTAL DE BACILLUS SPP EM UFC VIÁVEIS POR GRAMA DE RAÇÃO FARELADA E EXTRUSADA DURANTE 12 MESES.

\begin{tabular}{ccc}
\hline \multirow{2}{*}{ Tempo (meses) } & \multicolumn{2}{c}{ UFC/g de ração } \\
\cline { 2 - 3 } & Farelada & Extrusada \\
\hline 3 & $1,6 \times 10^{6}$ & $1,6 \times 10^{6}$ \\
6 & $1,6 \times 10^{6}$ & $1,4 \times 10^{6}$ \\
9 & $1,6 \times 10^{6}$ & $1,5 \times 10^{6}$ \\
12 & $1,6 \times 10^{6}$ & $1,6 \times 10^{6}$ \\
\hline
\end{tabular}

\footnotetext{
${ }^{1}$ Canigen - Virbac

2 VittaMax - Matsuda

${ }^{3}$ PETMAX Probiótico TR - IMEVE
} 
Avaliação da capacidade imunoestimulante e da estabilidade de um probiótico empregado em rações de cães

Os resultados dos títulos obtidos através da soro-aglutinação microscópica nos soros dos ani- mais dos dois grupos contra os sorovares canicola e icterohaenorrhagiae estão contidos na tabela 2.

TABELA 2 - RECÍPROCA DO TÍTULO VACINAL ANTI-CANICOLA E ANTI-ICTROHAEMORRHAGIAE DE 10 CÃES TRATADOS COM E SEM PROBIÓTICO TR NA RAÇÃO, NOS DIAS 15, 30 E 60 DO EXPERIMENTO.

\begin{tabular}{|c|c|c|c|c|c|c|c|}
\hline \multirow{3}{*}{ GRUPO } & \multirow{3}{*}{$\mathrm{N}^{\circ}$ DO ANIMAL } & \multicolumn{6}{|c|}{ RECÍPROCA DO TÍTULO VACINAL } \\
\hline & & \multicolumn{3}{|c|}{ CANICOLA } & \multicolumn{3}{|c|}{ ICTEROHAEMORRHAGIAE } \\
\hline & & 15 & 30 & 60 & 15 & 30 & 60 \\
\hline \multirow[t]{5}{*}{1} & 1 & 20 & 40 & 80 & 20 & 40 & 80 \\
\hline & 2 & 10 & 20 & 20 & 20 & 20 & 80 \\
\hline & 3 & 10 & 10 & 20 & 40 & 80 & 80 \\
\hline & 4 & 20 & 20 & 20 & 40 & 20 & 40 \\
\hline & 5 & 320 & 320 & 80 & 10 & 10 & 20 \\
\hline \multirow[t]{5}{*}{ II } & 6 & 40 & 80 & 80 & 40 & 20 & 10 \\
\hline & 7 & $\mathrm{~N}$ & $\mathrm{~N}$ & $\mathrm{~N}$ & 10 & 10 & $\mathrm{~N}$ \\
\hline & 8 & 40 & 20 & 40 & 20 & 20 & $\mathrm{~N}$ \\
\hline & 9 & 40 & 20 & 20 & 160 & 160 & 40 \\
\hline & 10 & $\mathrm{~N}$ & $\mathrm{~N}$ & $\mathrm{~N}$ & 80 & 40 & 40 \\
\hline
\end{tabular}

Não houve diferença significativa $(P>0,05)$ entre os valores dos hemogramas dos animais dos dois grupos, para cada dia em que foi realizado o exame, quando comparados com os valores antes da vacinação. Entretanto, na análise dos linfócitos observou-se diferença estatística (linfocitose) para os animais do grupo I em relação ao grupo II, alcançando nível máximo no $30^{\circ}$ dia decrescendo no $60^{\circ}$ dia (figura 1).

\section{FIGURA 1 - MÉDIA DO NÚMERO DE LINFÓCITOS OBTIDOS NOS HEMOGRAMAS DE CÃES VACINADOS CONTRA OS SOROVARES CANICOLA E ICTEROHAEMORRHAGIAE, ALIMENTADOS COM RAÇÃO COM E SEM PROBIÓTICO TR.}

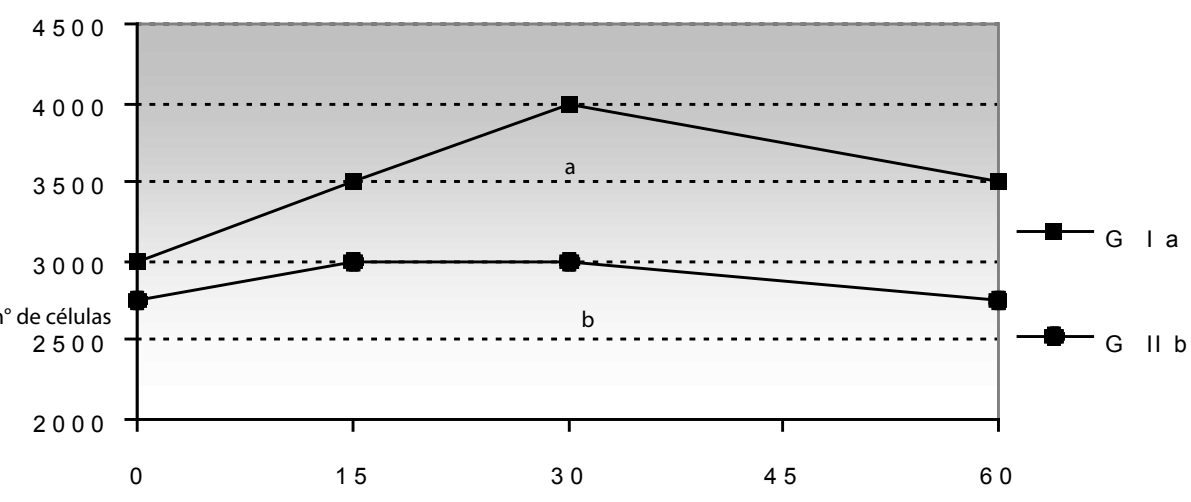

Dias a pós vacinação 
GONÇALVES, M. et al.

Com relação à consistência das fezes, no início do experimento, quatro animais do grupo I apresentavam fezes pouco pastosas e um animal fezes normais, no grupo II todos os animais apresentavam fezes normais. Ao final do experimento os animais dos dois grupos apresentavam fezes normais, havendo uma melhora na consistência para os animais que receberam ração com probiótico TR. Quanto ao ganho de peso, o grupo I ganhou em média $320 \mathrm{~g} \mathrm{e}$ o grupo II $300 \mathrm{~g}$ durante o experimento.

\section{DISCUSSÃO}

Pelos resultados da contagem total de esporos na ração extrusada, pode-se observar, na Tabela 1, que não houve perda de UFC de esporos, permanecendo viáveis e mantendo praticamente o mesmo número durante todo o tempo de estocagem. Este fato pode ser atribuído à incorporação do probiótico à ração após o processo de extrusão, quando a temperatura está em torno de $70^{\circ}$ a $80^{\circ} \mathrm{C}$, o que concorda com as recomendações de LIKIMANI e SOFOS (1990) e BIOURGE et al. (1998). A contagem total de esporos viáveis na ração farelada mostrou que eles permanecem com a mesma quantidade numérica durante todo o experimento. Diante destes resultados, o probiótico TR é notadamente estável em rações farelada e extrusada por períodos de até 12 meses quando adicionado após a extrusão.

Analisando os resultados dos títulos pós vacinais, mostrados na Tabela 2, para os animais dos dois grupos, pode-se observar que os do grupo II, cujos animais não receberam probiótico TR, no $15^{\circ}$ dia apresentaram títulos semelhantes aos do grupo I, que recebeu ração com probiótico TR. Entretanto, a partir do $30^{\circ}$ dia até o $60^{\circ}$ dia os animais do grupo I apresentaram uma elevação constante da resposta imune em relação aos animais do grupo II, cujos títulos diminuíram ou até desapareceram. A resposta imune para o antígeno canicola foi visivelmente menor que para o antígeno icterohaemorrhagiae, para os dois grupos, tendo no grupo II animais que nem título apresentou para aquele sorovar. Os animais do grupo I apresentaram elevação dos títulos anticanicola e anti- icterohaemorrhagiae ou mantiveram estáveis do $15^{\circ}$ até o $60^{\circ}$ dia. Na figura 1 , pode-se observar uma linfocitose estatisticamente significante para o grupo I em relação ao grupo II. Esta resposta coincide com o estímulo da resposta imune verificado pela elevação dos títulos dos animais do grupo I no $30^{\circ}$ e $60^{\circ}$. dia. Este fato deve ser atribuído à ingestão do probiótico TR (FULLER, 1989; LESTRADET, 2004), uma vez que entre os animais que não receberam ração com probiótico TR (grupo
II), a resposta imune foi instável e os linfócitos se mantiveram dentro da normalidade durante o período experimental. Outro fato relevante observado foi a melhora da consistência das fezes entre os animais alimentados com ração com probiótico TR, o que também é relatado por ÁVILA et al. (2000) alimentando bezerros com ração contendo probiótico.

\section{CONCLUSÃO}

O probiótico TR adicionado após a extrusão, é estável em rações farelada e extrusada por períodos de até 12 meses.

O probiótico TR estimula a resposta imune em cães vacinados contra os sorovares canicola e icterohaemorrhagiae.

\section{REFERÊNCIAS}

ÁVILA, F.A.; PAULILLO, A.C.; SCHOCKEN-ITURRINO, R.P.; LUCAS, F.A., ORGAZ, A.; QUINTANA, J.L. Avaliação da eficiência de um probiótico no controle de diarréia e no ganho de peso de bezerros. Arquivos Brasileiros de Medicina Veterinária e Zootecnia, v. 52, n. 1, p. 41-46, 2000.

BARROWS, G.T. DEAM, B.D. Using probiotics in small animals: a new approach. Veterinary Medicine, p. 36-42, 1985.

BIOURGE, V.; VALLET, C.; LEVESQUE, A.; SERGHERAET, R.; CHEVALIER, S.; ROBERTON, J.L. The use of probiotics in the diet of dogs. Journal of Nutrition, v. 128, n. 12, p. 2730-2732, 1998.

FULLER, R. Probiotics in man and animals. Journal Applied of Bacteriology, v. 66, p. 365-378, 1989.

KRASAEKOOPT, W.; BHANDARI, B.; DEETH, H. Evaluation of encapsulation techniques of probiotics for yoghurt. International Dairy Journal, v. 13, n. 1, p. 3-13, 2003.

LESTRADET, H. Probiotiques: utilization chez l'animal. Medicine Chirurgie Digestive, v. 23, p. 421-424, 2004.

LESTRADET, H. Probiotiques: le Bacillus CIP 5832 chez l'homme et l'animal. Medicine Chirurgie Digestive, v. 24, p. 37-39, 2005. 
Avaliação da capacidade imunoestimulante e da estabilidade de um probiótico empregado em rações de cães

LIKIMANI, T.A.; SOFOS, J.N. Bacterial spore injury during extrusion cooking of corn/soybean mixtures. International Journal of Food Microbiology, v. 11, p. 243-250, 1990.

MICHARD, J.; LEVESQUE, A. Stabilité du paciflor (Bacillus CIP 5832) dans les presentations commerciales et les aliments. Méthodes de dénombrement. Bulletin of Experimental Station Aviculture Ploufragan, v. 29: p. 146-151, 1989.

REBAR, A. H.; MACWILLIAMS, P. S.; FELDMAN, B. F.; METZGER, F. L.; POLLOCK, R. V. H.; ROCHE, J. Guia de hematologia para cães e gatos. São Paulo: Roca, 2003, 291p.

RENDE, J. C.; AVILA, F. A.. Leptospirose bovina: Perfil epidemiológico e dinâmico da infecção como zoonose. Ars Veterinária, v. 19, n. 1, p. 71-79, 2003.

SILVA, N.; JUNQUEIRA, V.C.A.; SILVEIRA, N.F.A. Manual de análise microbiológica de alimentos. $2^{\text {a }}$. ed., Livraria Varela, São Paulo, 2001, 317 p.

SCHREZENMEIR, J.; DE VRESE, M. Probiotics, prebiotics and symbiotics - approaching a definition. American Journal of Clinical Nutrition, v. 73, p. $361-364,2001$.

Recebido para publicação:

$11 / 04 / 2007$

Aprovado:

$30 / 11 / 2007$ 